\title{
ANTIOXIDANT POTENTIAL OF NOVEL DESIGNED PHENOLIC DERIVATIVES: COMPUTATIONAL INSIGHTS
}

\author{
Dinesh R. Pandithavidana ${ }^{1,}$, Kushani S. K. Hewage ${ }^{1}$
}

https://doi.org/10.23939/chcht14.04.448

\begin{abstract}
Density functional theory calculations were applied for designed phenolic antioxidant derivatives. The reaction enthalpies related to various mechanisms of primary antioxidant action were deliberated in detail. How antioxidant activity of designed phenolic compounds has been perturbed by electron donor and withdrawing substituents present at ortho, meta and para positions, allylic conjugation and the dimerization effect were computed.
\end{abstract}

Keywords: density functional theory, phenolic antioxidants, HAT mechanism, SET-PT mechanism.

\section{Introduction}

Among numerous types of antioxidant compounds, phenolic antioxidants form an important class of chainbreaking compounds, which have a potential to quench reactive radical intermediates formed during the oxidative processes of both biological and commercial importance materials [1-3]. Phenolic compounds are also mainly classified as secondary metabolites in plants and are divided into phenolic acids and polyphenols [3]. These compounds may exist as mono and polysaccharides, linked to one or more phenolic group, or can occur as derivatives, such as ester or methyl esters [2]. Among the numerous classes of phenolic antioxidants, the phenolic acids, flavonoids, and tannins are considered as the main dietary phenolic compounds [3]. According to the recent investigations, the possible role of antioxidants in prevention of human diseases has taken a leading role. Antioxidants are also capable to defend against a number of disease conditions such as aging, atherosclerosis, cancer, asthma, arthritis, and autoimmune diseases. Antioxidants as external supplements are used to maintain the concentration of free radicals as low as possible and to avoid the oxidative stress [4]. They are heavily used in food industry to maintain the quality of the ready-to-eat foods, and to boost the shelf life $[5,6]$.

\footnotetext{
${ }^{1}$ Department of Chemistry, Faculty of Science, University of Kelaniya, Kelaniya 11600, Sri Lanka

凶inesh@kln.ac.lk

(c) Pandithavidana D., Hewage K., 2020
}

The computational chemistry has become a versatile tool to investigate a wide range of thermodynamic properties which are hardly measurable, as well as to predict the trends between them. The efficiency of an antioxidant can be successfully estimated by analyzing the potential energy surface (PES) of the reaction with a certain radical. This potential energy surface permits calculation of the activation and reaction energies, entailing that both kinetic and thermodynamic approaches to the interested reaction are presented [6]. The computed parameters also provide useful information on the radical scavenging power without considering reaction pathway.

There are three major proposed mechanisms which can be used to clarify how antioxidants release the atomic hydrogen from their conjugated $\mathrm{OH}$ group to scavenge free radicals: (1) the hydrogen atom transfer (HAT) mechanism, (2) the single electron transfer-proton transfer (SET-PT) mechanism and (3) the sequential proton loss-electron transfer (SPLET) mechanism as illustrated in the Scheme [7, 8].

One of the most important parameters characterizing the antioxidant or radical scavenging activity of many natural and synthetic compounds is the bond dissociation enthalpy (BDE) that can be used to study the antioxidant potential of the HAT mechanism. The adiabatic ionization potential (IP) and the proton dissociation enthalpy (PDE) are utilized to determine antioxidant capacity of the SET-PT mechanism. Thus, the proton affinity (PA) and the electron transfer enthalpy (ETE) are used as thermodynamic parameters to investigate the antioxidant efficiency of the SPLET mechanism [7-9].

Although the Gibbs free energy represents a criterion of the thermodynamically feasible process, Klein and co-authors [9] have revealed for their investigated reactions that the absolute values of the entropic component are much smaller than the enthalpy component. Thus, comparison of BDEs, IPs, PDEs, Pas, and ETEs can illustrate which mechanism is thermodynamically preferred. Although these three mechanisms may or may not co-exist, the net end result of all these mechanisms is almost the same. 


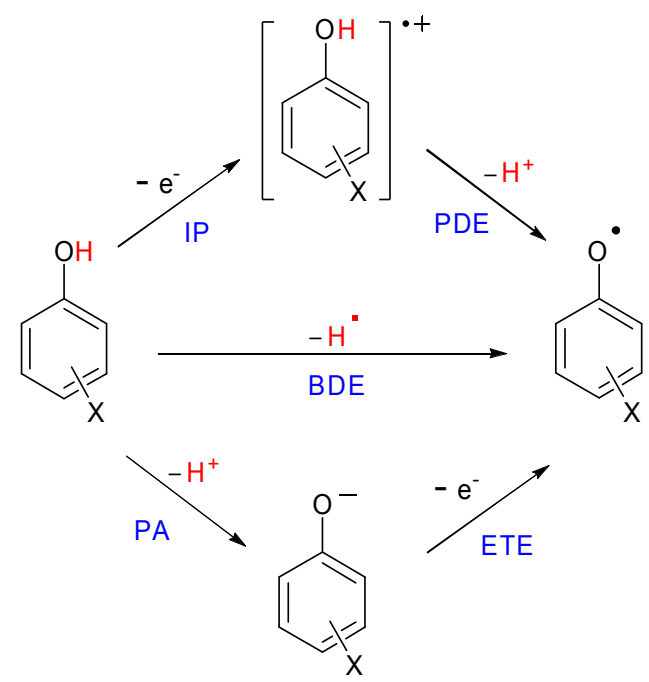

(1) HAT mechanism $=$ BDE

(2) $\mathrm{SET}-\mathrm{PT}$ mechanism $=\mathrm{IP}+\mathrm{PDE}$

(3) SPLET mechanism $=\mathrm{PA}+\mathrm{ETE}$

Scheme. Thermodynamic parameters used to investigate proposed mechanisms

Computational chemistry provides insight into the biological performance of phenolic antioxidants. Due to the presence of low cost and high precision performing calculations on the properties of phenolic compounds, density functional theory has been widely recognized as the most applicable computational methods for studying radical scavenging activities [10]. The comparisons between the experimental and theoretical data are not only able to make the controversially experimental facts clear, but also able to design novel compounds of commercial and pharmaceutical value.Although some computational studies have been carried out to investigate the antioxidant activity of phenolic antioxidants using HAT mechanism (as measuring BDE) [10-14], there was no any comparative study with other possible mechanisms such as SET-PT mechanism or SPLET mechanism. In this study we explore more thermodynamic parameters (as BDE, IP and PDE) to analyze and compare the antioxidant trends reveled by both HAT mechanism and SET-PT mechanism. All data computed in this study was modeled in aqueous phase because all radical scavenging activities take place in cellular environment which is rich in water $[15,16]$. Not only substituent effect (which was reported earlier) [17, 18] but also effect of an allylic conjugation and dimerization of phenols were also investigated to reveal the relationship between structure and reactivity. Thus, the effort made to find out such correlation from these thermochemical parameters may be helpful in shedding more light on this front.

\section{Experimental}

All DFT calculations have been performed using the Gaussian 09 program package with a desktop computer having Linux Mint 16 Cinnamon, 64 bit operating system (University of Colombo, Department of Chemistry, Colombo-03, Sri Lanka). The geometry of all phenolic compounds and their derivatives, including their radicals and radical cations have been fully optimized by employing the hybrid functional of BP86 level of theory with the basis set of 6-311++G (2df, 2p) [19].

Geometry optimizations were followed by vibrational analysis on all stationary points, to evaluate their character as minima. To compute the antioxidant potential of selected antioxidant molecules, the conformational space of the molecules has been explored in order to locate the structures of the global minima among all the possible conformers. For each molecule, a series of conformations being minima with energies close to this of the global minimum of the potential energy surface have been located.

Calculations were first carried out in the gas-phase as good primary indices for radical scavenging. Aqueous phase data were computed for geometries of optimized species, employing the conductor-like polarizable continuum model (CPCM solvation model). The thermodynamic properties of BDE, IP and PDE have been investigated in aqueous phase at $298.15 \mathrm{~K}$ following the formulae already applied on similar molecules $[19,20]$.

$$
\begin{gathered}
\mathrm{BDE}=\mathrm{H}\left(\mathrm{RO}^{\bullet}\right)+\mathrm{H}\left(\mathrm{H}^{\bullet}\right)-\mathrm{H}(\mathrm{ROH}) \\
\mathrm{IP}=\mathrm{H}\left(\mathrm{ROH}^{\bullet+}\right)+\mathrm{H}\left(\mathrm{e}^{-}\right)-\mathrm{H}(\mathrm{ROH}) \\
\mathrm{PDE}=\mathrm{H}\left(\mathrm{RO}^{\bullet}\right)+\mathrm{H}\left(\mathrm{H}^{+}\right)-\mathrm{H}\left(\mathrm{ROH}^{\bullet+}\right)
\end{gathered}
$$

The enthalpies of the protonated form, the radical form, and the radical cation form of the phenolic compounds have been represented as $\mathrm{H}(\mathrm{ROH}), \mathrm{H}\left(\mathrm{RO}^{\bullet}\right)$ and $\mathrm{H}\left(\mathrm{ROH}^{\bullet+}\right)$, respectively. The computed $\left(\mathrm{H}^{+}\right)$and $\mathrm{H}\left(\mathrm{e}^{-}\right)$ enthalpies were taken as 6.197 and $3.145 \mathrm{~kJ} \cdot \mathrm{mol}^{-1}$, respectively, from the literature available [20]. 


\section{Results and Discussion}

\subsection{Substituent Effect}

Benzene ring activated substituents $\left(-\mathrm{OCH}_{3}\right.$, $-\mathrm{C}_{2} \mathrm{H}_{5}$ and $\left.-\mathrm{NH}_{2}\right)$ as well as benzene ring deactivated substituents $\left(-\mathrm{NO}_{2},-\mathrm{CN}\right.$ and $\left.-\mathrm{COCH}_{3}\right)$ were introduced to the phenol at the positions of ortho, para and meta to investigate how antioxidant activity fluctuates due to the substituent effect. The electronic effect of the substituent is mainly composed of three parts: field effect, inductive effect, and resonance effect.

It was monitored through the thermodynamic properties of BDE (to support the HAT mechanism) IP and PDE (to support the SET-PT mechanism). Electronwithdrawing groups enhance $\mathrm{BDE}$ and IP, while the electron-donating groups reduce the BDE and IP.

The results mentioned in Table 1 revealed that the presences of electron donor substituents $\left(-\mathrm{OCH}_{3},-\mathrm{C}_{2} \mathrm{H}_{5}\right.$ and $-\mathrm{NH}_{2}$ ) have amplified the antioxidant activity significantly as lowering BDE, IP and PDE values with compared to the electron withdrawing substituents $\left(-\mathrm{NO}_{2}\right.$, $-\mathrm{CN}$ and $\left.-\mathrm{COCH}_{3}\right)$. The electronic effect of the substituents on the BDEs of methoxy phenols $\left(\mathrm{HO}-\mathrm{C}_{6} \mathrm{H}_{4}-\right.$ $\left.\mathrm{OCH}_{3}\right)$ and amino phenols $\left(\mathrm{HO}-\mathrm{C}_{6} \mathrm{H}_{4}-\mathrm{NH}_{2}\right)$ are mainly governed by the resonance effect, while that on the IPs and PDEs are mainly controlled by field and inductive effects. Since resulted phenoxide radicals are electro- philic, they are stabilized by the electron donor groups as perturbing the reaction center [21]. In most cases, the presence of electron donor group at the para position has facilitated additional stabilization to the system in comparison to that at the meta position.

According to our computational investigations, the $\mathrm{NH}_{2}$ substituted derivative is the strongest antioxidant in the aqueous phase studies, while the $\mathrm{NO}_{2}$ substituted derivative is the weakest one in the water phase. Although both HAT mechanism and SET-PT mechanisms may or may not take place simultaneously, the yield trend was almost the same [22].

\subsection{Effect of the Secondary and Tertiary Nature of Amino Substituents}

Since among the electron donor substituents, amino phenols $\left(\mathrm{HO}-\mathrm{C}_{6} \mathrm{H}_{4}-\mathrm{NH}_{2}\right)$ demonstrated the best antioxidant activity (Table 1), it was decided to design a secondary amine $\left(\mathrm{HO}-\mathrm{C}_{6} \mathrm{H}_{4}-\mathrm{NHCH}_{3}\right)$ and a tertiary amine $\left(\mathrm{HO}-\mathrm{C}_{6} \mathrm{H}_{4}-\mathrm{N}\left(\mathrm{CH}_{3}\right)_{2}\right)$ as substituted phenolic antioxidants and their radical scavenging properties were computed at ortho, meta and para positions in aqueous phase as shown in Table 2. It was demonstrated that values of BDE, IP and PDE had decreased noticeably. Both HAT mechanism and SET-PT mechanism confirmed that to observe the best antioxidant potential, the amino substituent should be tertiary and located at the para position of the phenol.

\section{Reaction enthalpies $\left(\mathrm{kJ} \cdot \mathrm{mol}^{-1}\right)$ in water for substituted phenols, employing functional of BP86 level} of theory with the basis set of 6-311++G (2df, $2 p)$

\begin{tabular}{|c|c|c|c|}
\hline Substituted phenol & Substituent position & HAT mechanism (BDE) & SET-PT mechanism (IP + PDE) \\
\hline \multirow{2}{*}{$\mathrm{HO}-\mathrm{C}_{6} \mathrm{H}_{4}-\mathrm{OCH}_{3}$} & ortho & 333.6 & 641.5 \\
& meta & 352.3 & 657.9 \\
\hline \multirow{2}{*}{$\mathrm{HO}-\mathrm{C}_{6} \mathrm{H}_{4}-\mathrm{C}_{2} \mathrm{H}_{5}$} & para & 320.9 & 691.7 \\
& ortho & 341.7 & 702.3 \\
\hline \multirow{2}{*}{$\mathrm{HO}-\mathrm{C}_{6} \mathrm{H}_{4}-\mathrm{NH}_{2}$} & meta & 349.1 & 690.2 \\
& para & 341.2 & 581.6 \\
\hline \multirow{2}{*}{$\mathrm{HO}-\mathrm{C}_{6} \mathrm{H}_{4}-\mathrm{NO}_{2}$} & meta & 293.4 & 691.2 \\
& para & 341.4 & 594.1 \\
\hline \multirow{2}{*}{$\mathrm{HO}-\mathrm{C}_{6} \mathrm{H}_{4}-\mathrm{CN}$} & ortho & 297.2 & 846.1 \\
& meta & 431.6 & 745.6 \\
\hline \multirow{2}{*}{$\mathrm{HO}-\mathrm{C}_{6} \mathrm{H}_{4}-\mathrm{COCH}_{3}$} & para & 369.6 & 792.2 \\
\hline & ortho & 375.7 & 679.5 \\
\hline
\end{tabular}


Reaction enthalpies $\left(\mathrm{kJ}^{\circ} \mathrm{mol}^{-1}\right)$ in water for amino substituted phenols, employing functional of BP86 level of theory with the basis set of 6-311++G (2df, 2p)

\begin{tabular}{|c|c|c|c|}
\hline Substituted phenol & Substituent position & HAT mechanism (BDE) & SET-PT mechanism (IP + PDE) \\
\hline \multirow{2}{*}{$\mathrm{HO}-\mathrm{C}_{6} \mathrm{H}_{4}-\mathrm{NHCH}_{3}$} & ortho & 299.5 & 516.2 \\
& meta & 313.1 & 533.6 \\
& para & 290.5 & 504.6 \\
$\mathrm{HO}-\mathrm{C}_{6} \mathrm{H}_{4}-\mathrm{N}\left(\mathrm{CH}_{3}\right)_{2}$ & ortho & 295.5 & 505.6 \\
& meta & 336.4 & 503.7 \\
& para & 288.2 & 492.1 \\
\hline
\end{tabular}

\subsection{Effect of Allylic Conjugated Substituents}

Thus ortho and para substituted $N, N-$ dimethylamino phenols (having a tertiary amine group) demonstrated a prominent antioxidant activity in aqueous phase studies, an allylic conjugated group was introduced (Fig. 1) to investigate the fluctuation of thermodynamic parameters of BDE, IP and PDE.

The computed results in Table 3 illustrated that the presence of "allylic conjugated group" on para substituted $\mathrm{N}, \mathrm{N}$-dimethylamino phenol possessed relatively lower enthalpies for BDE, IP and PDE as compared to ortho substituted $N, N$-dimethylamino phenol. This evinced that the presence of allylic substituents present at paraposition (1a) to the phenol and ortho-position to the phenol (1b) may stabilize the phenoxide radicals via inductive and field effect as donating electrons.

Polar protic solvents cause significant changes in the enthalpies of the ionic species. Thus, IP in the aqueous phase has been significantly lowered because of the fact that the cation radical is more stable and the conjugation of the $\pi$-electrons is more delocalized in the polar aqueous media.

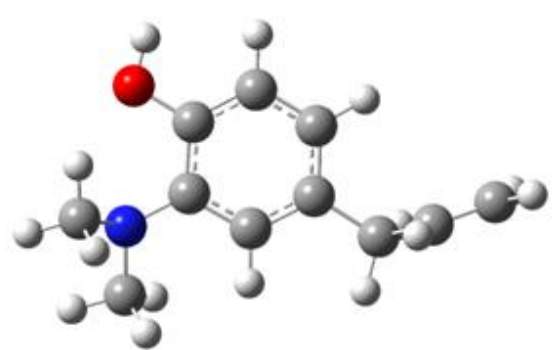

(la)

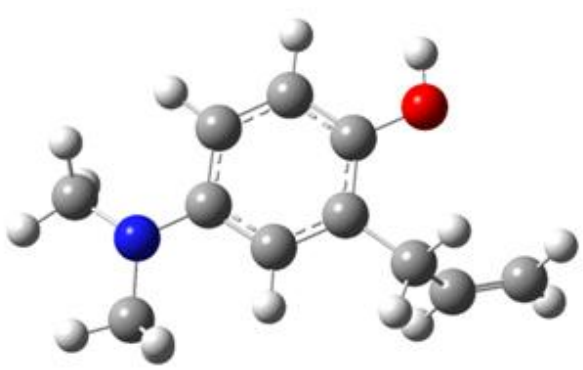

(lb)

Fig. 1. Optimized geometries of allylic (1a) and amino (1b) substituted phenols in aqueous phase.

Color atoms: for $\mathrm{O}, \mathrm{O}$ for $\mathrm{C}, \mathrm{O}$ for $\mathrm{N}$ and $\mathrm{for} \mathrm{H}$

Table 3

Reaction enthalpies $\left(\mathrm{kJ} \cdot \mathrm{mol}^{-1}\right)$ in water for allylic and amino substituted phenols (1a and 1b), employing functional of BP86 level of theory with the basis set of 6-311++G (2df, 2p)

\begin{tabular}{|l|l|l|}
\hline Substituted phenolic compounds & HAT mechanism (BDE) & SET-PT mechanism (IP + PDE) \\
\hline
\end{tabular}




\subsection{Effect of Allylic Conjugated and Non-conjugated Dimerized Substituents}

Thus $N, N$-dimethylamino phenols had lowered values of BDE, IP and PDE further, in the presence of an allylic conjugated group, the attention was focused to design dimmers (as shown in Fig. 2.) of $N, N$ dimethylamino phenols. Two of them (2a and $\mathbf{2 b})$ were dimerized via non-conjugated spacer (saturated alkyl chain) while the others (2c and 2d) were connected via conjugated (unsaturated) alkyl chain.

DFT studies predicted that conjugated dimmers have exhibited much better antioxidant properties (the lowest BDE) than their monomers and non-conjugated dimmers (Table 4).

These computed results revealed that the "dimerization with conjugation" is very crucial factor to enhance the antioxidant activity of design molecules. It has been also noticed that all these radicals benefit from the energetic stabilization arising from the hyperconjugation with the introduction of unsaturated spacer between two phenolic moieties (Fig. 3). Thus, with increase in conjugated spacer length, the stability of the radicals increases thereby, rendering them to show superior antioxidant ability.

Ionization potentials of these allylic conjugated dimerized phenolic antioxidants (2c, 2d) were also investigated separately in gas phase, in toluene (as a nonpolar medium) and in water (as a polar medium) as a comparative study (Table 5). It was revealed that the relative order of IP is water $<$ toluene $<$ gas phase. It came into sight that IP and PDE values are higher than the BDE values regardless of the solvent considered and the HAT mechanism is the obviously leading mechanism thermodynamically over the SET-PT mechanism.

It is apparent that the donation of the hydrogen (in HAT mechanism) has been affected by the polarity of solvents because of the change of BDE values. Therefore, in this study water was chosen as the major solvent because it is physiologically more relevant when in vivo antioxidant activity is concerned.<smiles>CN(C)c1cc(C/C=C/Cc2ccc(O)c(N(C)C)c2)ccc1O</smiles><smiles>CN(C)c1ccc(O)c(C/C=C/Cc2cc(N(C)C)ccc2O)c1</smiles><smiles>CN(C)c1cc(/C=C/C=C/c2ccc(O)c(N(C)C)c2)ccc1O</smiles><smiles>CN(C)c1ccc(O)c(/C=C/C=C/c2cc(N(C)C)ccc2O)c1</smiles>

Fig. 2. Allylic non-conjugated dimerized phenolic antioxidants; (2a, 2b) and allylic conjugated dimerized phenolic antioxidants $(\mathbf{2 c}, \mathbf{2 d})$

Table 4

Reaction enthalpies $\left(\mathrm{kJ}^{\mathrm{m}} \mathrm{mol}^{-1}\right)$ in water for allylic both conjugated and non-conjugated dimerized phenolic antioxidants, employing functional of BP86 level of theory with the basis set of 6-311++G(2df, 2p)

\begin{tabular}{|c|c|c|}
\hline Dimerized phenolic antioxidants & HAT Mechanism (BDE) & SET-PT Mechanism (IP + PDE) \\
\hline $\mathbf{2 a}$ & 294.5 & 516.2 \\
$\mathbf{2 b}$ & 289.1 & 533.6 \\
\hline $\mathbf{2 c}$ & 270.5 & 505.6 \\
$\mathbf{2 d}$ & 262.1 & 503.7 \\
\hline
\end{tabular}


(2a)

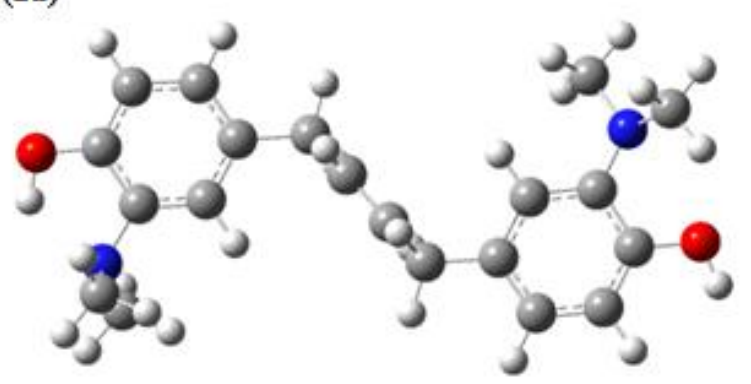

(2c)

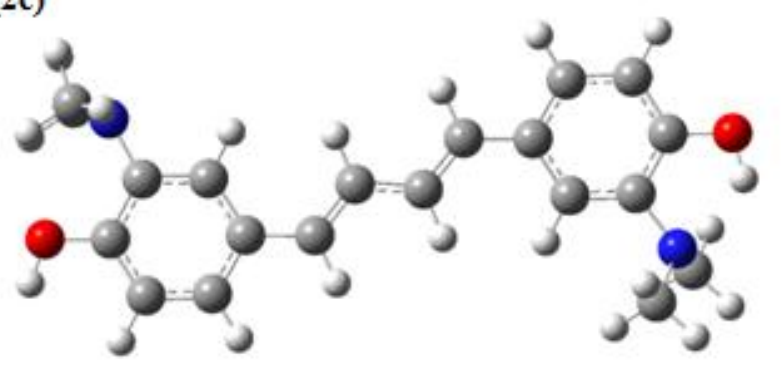

(2b)

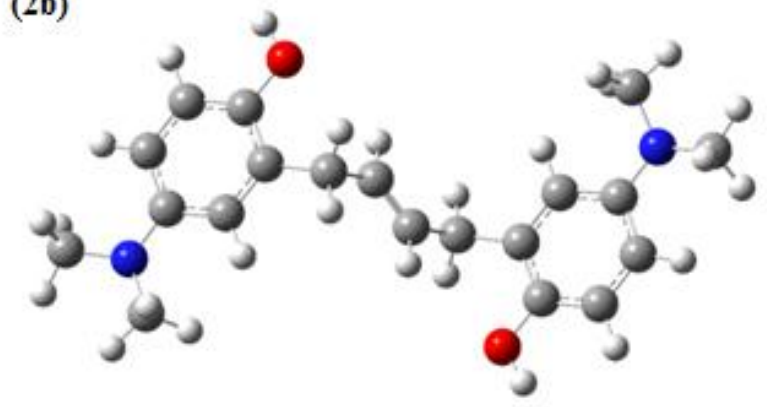

(2d)

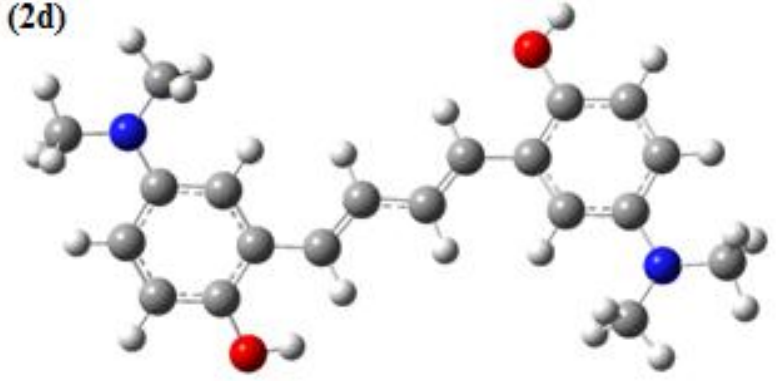

Fig. 3. The optimized geometries of allylic non-conjugated (2a, $\mathbf{2 b})$ and conjugated $(\mathbf{2} \mathbf{c}, \mathbf{2 d})$ dimerized phenolic antioxidants in aqueous phase. Color atoms: for $\mathrm{O}$, for $\mathrm{C}$, for $\mathrm{N}$ and for $\mathrm{H}$

Table 5

The comparison of reaction enthalpies in $\mathrm{kJmol}^{-1}$ in water, toluene and gas phase for allylic conjugated dimerized phenolic antioxidants, employing functional of BP86 level of theory with the basis set of 6-311++G(2df, 2p)

\begin{tabular}{|c|c|c|c|}
\hline Dimerized phenolic antioxidants & Phase & HAT mechanism (BDE) & SET-PT mechanism (IP + PDE) \\
\hline \multirow{2}{*}{$2 c$} & Water & 270.5 & 505.6 \\
& Toluene & 279.1 & 539.6 \\
& Gas & 284.7 & 558.2 \\
\hline \multirow{2}{*}{$2 d$} & Water & 262.1 & 503.7 \\
& Toluen & 276.5 & 535.6 \\
& Gas & 282.1 & 540.7 \\
\hline
\end{tabular}

According to our DFT investigations, the SET-PT mechanism involves a greater energy expense with respect to the HAT mechanism. It is noteworthy that each reaction step involved in the analyzed mechanisms should be fully explored to unambiguously determine the reasons for which such mechanism is the preferential one. This was another goal of this work which was aimed to provide a comparison on the antioxidant ability of novel designed phenolic derivatives by evaluating the known descriptors of antioxidant properties.

\section{Conclusions}

According to the computational investigations, in aqueous phase the designed phenolic antioxidants showed better activity owing to hydrogen bonding. Moreover, the polarity of the medium has lowered the $\mathrm{O}-\mathrm{H}$ BDE values, suggesting their superior $\mathrm{H}$-atom transfer capacity in water like polar solvent. Presence of electron donating substituents on the structure at ortho and para positions of the phenolic antioxidants have enhanced their antioxidant activity significantly. The impact of solvent effect on ionization potential (IP) was more pronounced than that of on BDE showing that the SET-PT mechanism was highly solvent dependent compared to the HAT mechanism. The calculated BDE demonstrated that with increase in spacer length, the $\mathrm{H}$-atom transfer becomes more prominent. It was also evident that dimerization of phenolic derivatives via unsaturated alkyl chains (extending the conjugation between two phenolic groups) have yielded two hydroxyls moieties per antioxidant molecule, which has noticeably increased the antioxidant activity. The calculated vertical ionization potential (IP) values also confirmed that with increase in spacer length, single electron transfer from these novel designed phenolic derivatives becomes easy, making them commercially beneficial antioxidants. This 
study provides insight to designed, structurally novel, simple antioxidants (as compared to the natural antioxidants) which will be more economical and beneficial in pharmaceutical industry.

\section{Acknowledgements}

The authors are thankful to Department of Chemistry, University of Colombo for allowing to use the Gaussian 09 program package with a desktop computer having Linux Mint 16 Cinnamon, 64 bit operating system.

\section{References}

[1] Lobo V., Patil A., Phatak A., Chandra N.: Pharm. Rev., 2010, 4, 118. https://doi.org/10.4103/0973-7847.70902

[2] Nimse S., Pal D.: RSC Adv., 2015, 5, 27986.

https://doi.org/10.1039/C4RA13315C

[3] Brewer M.: Rev. Food Sci. Food Saf., 2011, 10, 221.

https://doi.org/10.1111/j.1541-4337.2011.00156.x

[4] Dizdaroglu M.: Mutat Res. DNAging., 1992, 275, 331.

https://doi.org/10.1016/0921-8734(92)90036-O

[5] Mohajeri S., Asemani S.: J. Mol. Struct., 2009, 930, 15.

https://doi.org/10.1016/j.molstruc.2009.04.031

[6] Skorna P., Rimarcík J., Poliak P. et al.: Comp. Theor. Chem.,

2016, 1077, 32. https://doi.org/10.1016/j.comptc.2015.10.010

[7] Pandithavidana D., Jayawardana S.: Molecules, 2019, 24, 1646. https://doi.org/10.3390/molecules24091646

[8] Mazzone G., Russo N., Toscano M.: Comp. Theor. Chem.,

2016, 1077, 39. https://doi.org/10.1016/j.comptc.2015.10.011

[9] Borgohain R., Guha A., Pratihar S., Handique J.: Comp. Theor. Chem., 2015, 1060, 17.

https://doi.org/10.1016/j.comptc.2015.02.014

[10] Mulder P., Saastad O., Griller D.: J. Am. Chem. Soc., 1988, 110, 4090. https://doi.org/10.1021/ja00220a088

[11] Bordwell F., Zhang X., Satish A., Cheng J.: J. Am. Chem. Soc., 1994, 116, 6605. https://doi.org/10.1021/ja00094a015
[12] Lind J., Shen X., Eriksen T., Merenyi G.: J. Am. Chem. Soc., 1990, 112, 479. https://doi.org/10.1021/ja00158a002

[13] Bordwell F., Cheng J.: J. Am. Chem. Soc., 1991, 113, 1736. https://doi.org/10.1021/ja00005a042

[14] Brinck T., Haeberlein M., Jonsson M.: J. Am. Chem. Soc., 1997, 119, 4239. https://doi.org/10.1021/ja962931+

[15] Kamat J., Devasagayam T.: Redox Rep., 1999, 4, 179. https://doi.org/10.1179/135100099101534882

[16] Klein E., Lukeš V., Ilcin M.: Chem. Phys., 2007, 336, 51. https://doi.org/10.1016/j.chemphys.2007.05.007

[17] Chandra K., Uchimaru T.: Int. J. Mol. Sci., 2002, 3, 407. https://doi.org/10.3390/i3040407

[18] Klein E., Lukeš V.: J. Phys. Chem. A, 2006, 110, 12312. https://doi.org/10.1021/jp063468i

[19] Mazzone G., Malaj N., Russo N., Toscano M.: Food Chem., 2013, 141, 2017. https://doi.org/10.1016/j.foodchem.2013.05.071

[20] Mazzone G., Malaj N., Galano A., et al..: RSC Adv., 2015, 5, 565. https://doi.org/10.1039/C4RA11733F

[21] Wright J., Johnson E., DiLabio G.: J. Am. Chem. Soc., 2001, 123, 1173. https://doi.org/10.1021/ja002455u

[22] Becke A.: Phys. Rev. A, 1988, 38, 3098.

https://doi.org/10.1103/PhysRevA.38.3098

Received: October 10, 2019 / Revised: November 18, 2019 /

Accepted: January 12, 2020

\section{АНТИОКСИДАНТНИЙ ПОТЕНЦІАЛ НОВИХ ФЕНОЛЬНИХ ПОХІДНИХ: КОМП'ЮТЕРНИЙ АНАЛІЗ}

Анотація. Для розроблення похідних фенольних антиоксидантів застосовані розрахунки згідно теорії функціоналу густини. Детально проаналізовано ентальпії реакиій відносно різних механізмів первинної антиоксидантної діі. Розраховано вплив електронних донорів, орто-, мета- та пара-положень замісників, аллільного спряження та димеризації на антиоксидантну активність розроблених фенольних сполук.

Ключові слова: теорія функиіоналу густини, фенольні антиоксиданти, механізм НАT, механізм SET-PT. 